\title{
Reduced gait automaticity in female patients with chronic fatigue syndrome: Case-control study
}

\author{
Jan b Eyskens, MSc PT, DO, Pr Ph; ${ }^{*}$ Jo Nijs, PhD; $^{2}$ Kristien Wouters; ${ }^{3-4}$ Greta Moorkens, MD, PhD ${ }^{1,4}$ \\ ${ }^{1}$ Department of Internal Medicine, Antwerp University Hospital, Antwerp, Belgium; ${ }^{2}$ Pain in Motion Research Group, \\ Departments of Human Physiology and Physiotherapy, Vrije Universiteit Brussel, Brussels, Belgium, and Department \\ of Physical Medicine and Physiotherapy, University Hospital Brussels, Brussels, Belgium; ${ }^{3}$ Department of Scientific \\ Coordination and Biostatistics, Antwerp University Hospital, Antwerp, Belgium; ${ }^{4}$ Faculty of Medicine and Health \\ Science, University of Antwerp, Antwerp, Belgium
}

\begin{abstract}
Patients with chronic fatigue syndrome (CFS) report difficulties walking for a prolonged period of time. This study compares gait automaticity between women with CFS and nondisabled controls. The "stops walking with eyes closed with secondary cognitive task" test is based on the classic "stops walking while talking" test but compares walking with eyes closed while performing a secondary cognitive task in a female CFS population $(n=34)$ and in female nondisabled controls $(n=38)$. When initiating gate, $23.5 \%$ of patients with CFS looked toward the ground compared with only $2.6 \%$ of nondisabled controls. After $7 \mathrm{~m}$, subjects were asked to close their eyes, and after another $7 \mathrm{~m}$, they were asked, "How much is 100 minus 7 ?" Of the patients with CFS, $55.9 \%$ stopped walking compared with $5.3 \%$ of nondisabled controls. Less automated walking was observed in patients with CFS than in nondisabled controls $(p<0.001)$. The test-retest reliability is moderate for global stopping. This simple test observed reduced gait automaticity in patients with CFS for the first time. Dual tasking could be helpful to address the functional limitations found in this particular study.
\end{abstract}

Key words: automaticity of walking, balance, chronic fatigue syndrome, dual tasking, gait, graded exercise therapy, movement, physical performance, timed loaded standing, vision.

\section{INTRODUCTION}

Chronic fatigue syndrome (CFS) is defined by the U.S. Centers for Disease Control and Prevention (CDC) as a condition characterized by self-reported, unexplained, persistent, or relapsing fatigue of at least 6 mo duration and the concurrent occurrence of multiple nonspecific symptoms, including sore throat, muscle and joint pain, headache, tender cervical or axillary lymph nodes, unrefreshing sleep, and postexertional malaise [1]. Complaints related to vision or vision-related tasks are often mentioned by patients with CFS [2], and these patients typically report difficulties when standing or walking for a prolonged time [3-5].

\footnotetext{
Abbreviations: $\mathrm{CDC}=$ U.S. Centers for Disease Control and Prevention, CFS = chronic fatigue syndrome, DT $=$ dual tasking, GET = graded exercise therapy, SWECCT = stops walking with eyes closed with secondary cognitive task, SWWT = stops walking while talking, TLS = timed loaded standing.

*Address all correspondence to Jan b Eyskens, MSc PT, DO, Pr Ph; Rijsenbergstraat 31, 9000 Ghent, Belgium; +32-486-50-70-01. Email: jan@beweging.org

http://dx.doi.org/10.1682/JRRD.2014.11.0293
} 
In a previous study using the timed loaded standing (TLS) test, female patients with CFS showed lower combined trunk and arm endurance than female nondisabled controls, women living in nonindustrialized countries with no diagnosis of CFS, and even older female osteoporotic patients [6-7]. These findings might indicate patients with CFS are restricted in their ability to hold themselves upright against gravity.

The results from the TLS study in patients with CFS could be understood in parallel with poor working posture [8]. A relation has been shown between poor working posture and musculoskeletal disorders, stress, and discomfort [9-12]. When working positions are not optimal, visual requirements have a greater influence on working posture than manual or bodily requirements [13-17]. The role of vision in controlling the direction and speed of gait is important, especially in complex and/or dark environments [18].

The combined actions of walking and talking have been studied in nondisabled populations [19-21] and are affected by age. In the elderly, the "stops walking while talking" (SWWT) test has been found to be a good predictor of falls among frail, institutionalized elderly patients [22-24]. No information on initiating or stopping walking in patients with CFS was found in the literature. Most patients with CFS do not reach the daily recommended 10,000 steps [25]. Patients with CFS walk slower but also at a higher cost at matched velocity than nondisabled controls [26].

It is not common practice to check for visual impairment in patients with CFS. However, patients with CFS show impairments in visual accommodation, are more sensitive to light than nondisabled controls [27], and often report floaters as well as tear-related problems [28]. Research findings point to reduced visual capabilities (including reduced car driving capacity) [27], slower tracking ability for moving objects, and worse visual attention [2,29-30] in patients with CFS.

Along with vision, cognitive performance is reduced in patients with CFS [31-32]. When two concurrent tasks ask for more capacity than available, one of the tasks will be impaired or even stopped [33]. Nondisabled people are able to talk while walking or to walk with their eyes closed. However, as soon as automaticity is lost, the compensatory costs increase [34-35]. Combining walking, talking, and paying specific visual attention to the surroundings can be difficult in patients with CFS [36]. To date, studies examining dual tasking (DT) in patients with CFS are unavailable. This also accounts for studies examining DT in relation to vision and walking in patients with CFS.

In order to compare and evaluate walking with eyes closed and performing a secondary cognitive task in a CFS population and in nondisabled controls, our group developed a new test entitled "stops walking with eyes closed with secondary cognitive task" (SWECCT), based on the SWWT test by Lundin-Olsson et al. [37] but adapted to the CFS population.

The SWWT test is a relatively simple physical test that challenges parallel motor and cognitive tasks; it has been found to be a good predictor of falls among frail, institutionalized elderly patients [37]. The SWWT test shows good specificity (95\%) and acceptable positive predictive values (83\%) along with negative predictive values (76\%) with moderate sensitivity $(48 \%)$ in the prediction of falls [38-41].

For the reasons outlined previously, the present study has three aims: (1) examine whether gait automaticity is different between patients with CFS and nondisabled controls, (2) examine the test-retest reliability of the SWECCT test for assessing gait automaticity in patients with CFS, and (3) examine whether impairment in gait automaticity is associated with combined trunk and arm endurance in patients with CFS.

First, we hypothesized that patients with CFS would show reduced gait automaticity compared with nondisabled controls. Second, we hypothesized that the SWECCT test would generate reliable data for assessing gait automaticity in patients with CFS. Third, we hypothesized that gait automaticity would be associated with combined trunk and arm endurance in patients with CFS.

\section{METHODS}

\section{Study Participants}

In total, 72 study participants were enrolled and completed the study. The CFS population $(n=34)$ were Belgian, Caucasian, Dutch-speaking, nonpregnant women (20-56 yr old; mean: 41 yr) who fulfilled the 1994 CDC diagnostic criteria [1]. Patients were evaluated and recruited by one physician (G.M.), who specializes in internal medicine and has extensive experience in diagnosing patients with CFS, at the outpatient clinic of general internal medicine at the Antwerp University Hospital (Antwerp, Belgium). All patients were carefully screened for other possible medical causes, signs, and symptoms, 
as is required for the diagnosis of CFS [42]. This implies standard blood testing and endocrinological, cardiac, pulmonary, and neurological screens as well as psychiatric screening.

The nondisabled female controls $(n=38)$ consisted of nurses and physicians recruited from the participating hospital (31-48 yr old; mean: 40 yr). Study participants were not allowed to report sick leave during the last 24 mo, were pain free, and were without any (chronic) disease at the time of study participation.

\section{Study Design}

The study was designed as a cross-sectional and casecontrolled comparison. The SWECCT test of patients with CFS and nondisabled controls was performed at the outpatient clinic of the general internal medicine department at the Antwerp University Hospital.

The study protocol was approved by the Ethics Committee of the Antwerp University Hospital. Study recruitment was performed by distribution of oral and written information at the outpatient clinic. Written informed consent was obtained from all participants. After collecting information on personal characteristics, the DT test was completed. In order to prevent bias due to pooling of sex data, only females were allowed to participate [7].

\section{Procedures}

Stops Walking With Eyes Closed With Secondary Cognitive Task

We developed a low-tech, clinically applicable test entitled the SWECCT. The test is based on the classic SWWT test by Lundin-Olsson et al. first published in 1997 [37]. The SWWT test can be described as follows: patients walked with the eyes open, and when the examiner started a conversation, the patient either stopped when answering or went on walking.

Because our experience was that patients with CFS had difficulties positioning themselves in space when lacking visual data, we adapted the SWWT test to the SWECCT test, which consists of three phases: (1) initiation of gait with eyes open, (2) sustaining gait or stopping after closing the eyes, and (3) sustaining or stopping gait with eyes still closed when answering a simple cognitive question, "How much is 100 minus 7 ?"

Subjects were placed along a quiet hospital corridor and asked to look in front of them. They were instructed to walk through the corridor at a normal pace as long as they could and informed that thereafter, at two consecutive times, another task would be given. We repeated that they had to continue walking as long as they could, adding that they would be safe because we would walk near them. During instructions, we stood $2 \mathrm{~m}$ in front of the subjects, a bit to the side, and checked whether their eyes were still aimed at the corridor's end [43]. We followed the subjects without any other intervention, except for instructing the two additional tasks and ensuring their safety.

The SWECCT test uses the following procedure (Figure 1). At point $A$, we asked the subject to initiate walking. After $7 \mathrm{~m}$ (point B), we asked the subject to close her eyes, and after another $7 \mathrm{~m}$ (point C), we asked "How much is 100 minus 7?"

This made it possible to not only observe but also to quantify the combined functioning of balance, gait, vision, strength, and coordination with eyes closed and during performance of a simple cognitive task.

- At point A: Did subjects focus their eyes toward their feet or the ground when initiating gait? A score of 0 was given if no deterioration could be observed. A

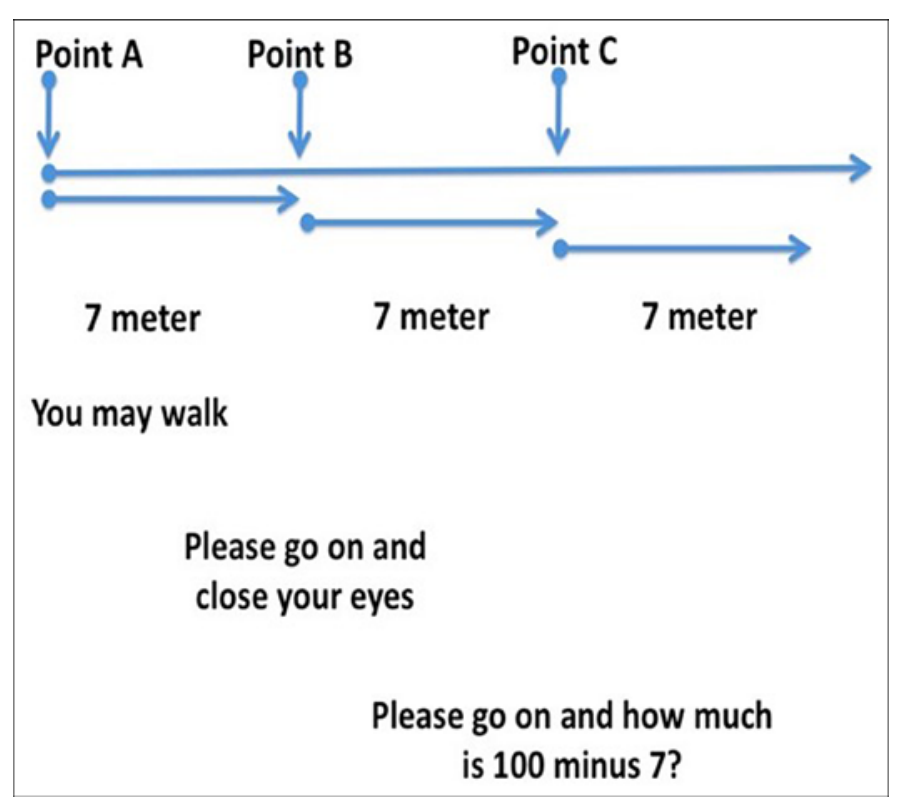

Figure 1.

Scheme of "stops walking with eyes closed with secondary cognitive task" test. Point A: Starting position, subject standing with eyes aimed at end of corridor. Point B: After $7 \mathrm{~m}$, ask subject to close eyes while walking. Point $\mathrm{C}$ : After another $7 \mathrm{~m}$, ask subject to continue walking with eyes closed and ask "How much is 100 minus 7?" 
score of 1 was given if eyes were aimed at the ground when initiating gait.

- At point B: Did closing the eyes deteriorate gait? Did it make them stop walking? In order to register the observations in real time, the following codes were used at points $\mathrm{B}$ and $\mathrm{C}$. If no deterioration could be observed, the score was 0 ; for slight deterioration (slowing down or extending the arms to keep balance), the score was 1 . A score of 2 was given if subjects lost direction or changed their pace dramatically. If subjects opened their eyes, stopped, or had to be stopped for safety, a score of 3 was given.

- At point C: Did an additional cognitive task, while continuing to walk with eyes still closed, deteriorate gait? The same scoring system was used as in point B.

Not one subject, patient with CFS or nondisabled control, had to be stopped for safety reasons. No one lost direction in such a way that they had to be stopped in order not to collide with the wall. No one opened her eyes to continue walking.

The test was performed once by nondisabled controls and twice-with an interval of $<1$ min-by patients with CFS. This was done in order to examine the test-retest reliability of the SWECCT test in patients with CFS. The short test-retest time interval was chosen not only for obvious convenience reasons but also to prevent the fluctuating nature of CFS patients' symptoms to interfere with the reliability testing.

\section{Timed Loaded Standing}

For TLS, a test originally used by Shipp et al. [6] in osteoporotic patients, we refer to our article in a population of patients with CFS comparing them to nonindustrialized, osteoporotic, and nondisabled populations [7].

TLS measures the time (in seconds) a person can stand while holding a $1 \mathrm{~kg}$ dumbbell in each hand with the arms at $90^{\circ}$ of shoulder flexion with elbows extended and wrists in neutral pronation/supination (Figure 2). The TLS test is a physical performance measure of combined trunk and arm endurance, simulating functional performance of the trunk in daily activities, most of which require the trunk to remain erect and stable while the upper limbs are used [6]. TLS has been shown to generate reliable data, with good intraclass correlation coefficients for same day test-retest and 6 to $10 \mathrm{~d}$ test-retest reliability in 127 osteoporotic women with vertebral fractures [6].

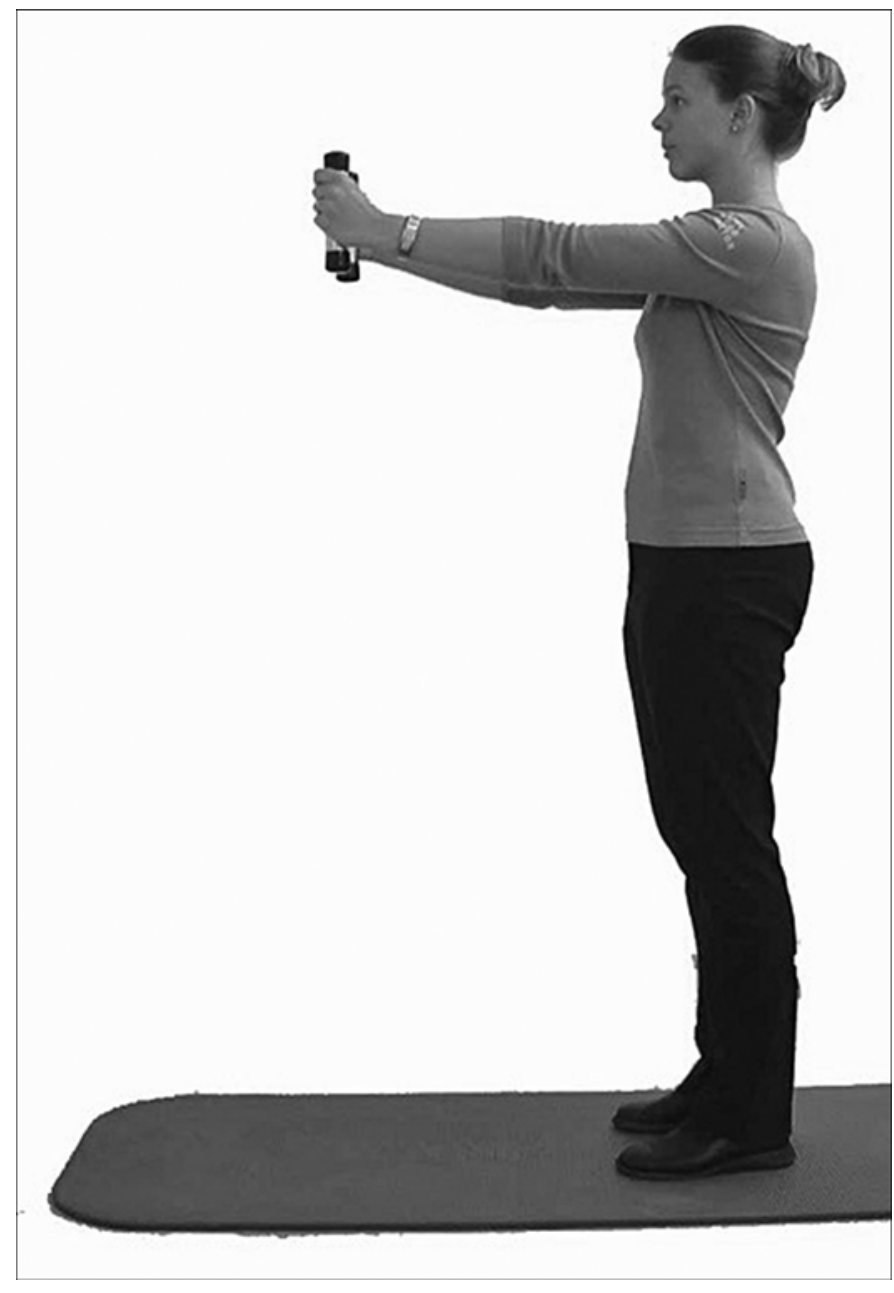

Figure 2.

Timed loaded standing test. For equipment and specific procedure, see Shipp et al. [6] and Eyskens et al. [7]. This figure was previously published in Eyskens et al. [7].

\section{Statistical Analysis}

To compare the percentage of patients and nondisabled controls who stopped walking, a chi-square test was used. When numbers were small, a Fisher exact test was performed. The actual scoring of the test at each point, ranging from 0 to 3 , was compared between both groups with a Mann-Whitney $U$ test. Agreement between test and retest was assessed by weighted kappa coefficients. Interpretation of kappa coefficients is done according to Landis and Koch [44].

The Spearman correlation coefficient was calculated to examine the association between the data from the TLS with the SWECCT data. To describe the relationship between TLS and SWECCT test results, a linear regression 
model was used. The square root of TLS was used in order to achieve normality of the residuals.

Logistic regression models were fitted to discriminate between patients with CFS and a nondisabled population on TLS and/or SWECCT results. For these models, sensitivity, specificity, and accuracy are reported.

\section{RESULTS}

\section{Comparing Gait Automaticity Between Patients with} Chronic Fatigue Syndrome and Nondisabled Controls

Table 1 shows the demographic data for both populations, patients with CFS and nondisabled controls. Since the nondisabled control group was tested only once, only the results from the first test of patients with CFS were used for comparison. Table 2 shows the main findings of the SWECCT test in patients with CFS versus nondisabled controls. Of the patients with CFS, 55.9 percent stopped walking during test performance compared with only 5.3 percent in the control group $(p<0.001)$.

Then, findings are shown for each point. Already at point A (Table 2), a difference between both groups can be noted. Of the patients with CFS, eight (23.5\%) looked toward the ground and/or at their feet before initiating gate compared with only one (2.6\%) control subject ( $p=$ 0.01).

Table 1.

Demographic data for female patients with chronic fatigue syndrome (CFS) $(n=34)$ and nondisabled controls $(n=38)$. Normally distributed parameters represented as mean \pm standard deviation; for non-normally distributed data, median (Q1-Q3) is given.

\begin{tabular}{lcc}
\hline \multicolumn{1}{c}{ Demographic } & Nondisabled Controls & Patients with CFS \\
\hline Age $(\mathrm{yr})$ & $40 \pm 10$ & $41 \pm 8$ \\
Height $(\mathrm{cm})$ & $167.3 \pm 6.5$ & $163.9 \pm 5.3^{*}$ \\
Weight $(\mathrm{kg})$ & $63.0(57.0-69.8)$ & $64.3(55.0-71.5)$ \\
Body Mass Index $\left(\mathrm{kg} / \mathrm{m}^{2}\right)$ & $22.1(21.0-23.4)$ & $23.3(20.6-26.5)$ \\
Body Surface $\left(\mathrm{m}^{2}\right)$ & $1.66 \pm 0.16$ & $1.63 \pm 0.18$ \\
\hline${ }^{*} p<0.05$. & & \\
$\mathrm{Q}=$ quartile. & & \\
\hline \hline
\end{tabular}

Table 2.

Gait automaticity in female patients with chronic fatigue syndrome (CFS) $(n=34)$ and nondisabled controls $(n=38)$ using "stops walking with eyes closed with secondary cognitive task" test, $n(\%)$.

\begin{tabular}{lccc}
\hline \multicolumn{1}{c}{ Gait Automaticity } & Nondisabled Controls & Patients with CFS & $\boldsymbol{p}$-Value \\
\hline Stopped During Test & $36(94.7)$ & $15(44.1)$ & $<0.001$ \\
$\quad$ No & $2(5.3)$ & $19(55.9)$ & 0.01 \\
Yes & & & \\
Findings at Point A & $37(97.4)$ & $26(76.5)$ & $<(23.5)$ \\
$\quad$ No Deterioration & $1(2.6)$ & & $<0.001$ \\
Look at Feet Before Start & $31(81.6)$ & $4(11.8)$ & $<0.001$ \\
Findings at Point B (eyes closed) & $6(15.8)$ & $17(50.0)$ & $10(29.4)$ \\
$\quad$ No Deterioration & $1(2.6)$ & $3(8.8)$ & \\
Slight Deterioration & $0(0.0)$ & $0(0.0)$ & \\
Severe Deterioration & & $2(5.9)$ & \\
Stopped Walking & $13(34.2)$ & $13(38.2)$ & \\
Findings at Point C (cognitive task) & $17(44.7)$ & $19(55.9)$ & \\
No Deterioration & $6(15.8)$ & & \\
Slight Deterioration & $2(5.3)$ & & \\
Severe Deterioration & & & \\
Stopped Walking & & & \\
\hline
\end{tabular}


At point B, after closing their eyes, 8.8 percent of patients with CFS stopped walking compared with no subjects in the nondisabled control group $(p=0.10)$. Significantly more patients with CFS deteriorated dramatically or even stopped walking at point B compared with the control group (38.2\% vs $2.6 \%, p=0.001$ ).

\section{Test-Retest Reliability of SWECCT Test in Patients With Chronic Fatigue Syndrome}

Table 3 shows the results of the test-retest in patients with CFS. Of the 19 patients who stopped walking in the first test, 12 also stopped in the second test, and 2 patients who didn't stop in the first test stopped in the second.

At point A, eight patients with CFS focused their eyes on the ground before initiating gait. One patient who did not look toward the ground before walking did so during the second test. At the same time, one patient who looked toward the ground during the first test did not do so during the second. At point B, three patients stopped twice. It seemed that six patients walked less unbalanced during the second test, while one patient had more difficulties. At point C, 22 patients had the same level of deterioration in both tests, but 10 patients had fewer deterioration problems in the second test.

The agreement between the first and second test is high at points $\mathrm{A}$ and $\mathrm{B}$ (kappa $=0.84$ and 0.85 , respectively) but much lower at point C (kappa $=0.55)$ and for global stopping/no stopping $($ kappa $=0.48)($ Table 3$)$. At point $\mathrm{C}$, a lot of patients improved as a result of performing the test twice. The test-retest reliability for point $\mathrm{C}$ and global stopping of the SWECCT test is moderate.

\section{Is Gait Automaticity in Patients with Chronic Fatigue Syndrome Related to Their Trunk and Arm Endurance?}

The results of the TLS test in patients with CFS have been presented in a previous article [7]. Figure 3 shows

\section{Table 3.}

Test-retest reliability of "stops walking with eyes closed with secondary cognitive task" test in female patients with chronic fatigue syndrome by number of patients $(n=34)$ : continuing or cessation of walking.

\begin{tabular}{lcccc}
\hline Test & $\begin{array}{c}\text { Test 1 } \mathbf{~} \\
\text { Test 2 }\end{array}$ & $\begin{array}{c}\text { Test 1 } \\
\text { Test 2 } \\
\text { (Worsening) }\end{array}$ & $\begin{array}{c}\text { Test 1 }> \\
\text { Test 2 } \\
\text { (Improving) }\end{array}$ & $\begin{array}{c}\text { Weighted } \\
\text { Kappa }\end{array}$ \\
\hline Stopped & 25 & 2 & 7 & 0.48 \\
Point A & 32 & 1 & 1 & 0.84 \\
Point B & 27 & 1 & 6 & 0.85 \\
Point C & 22 & 2 & 10 & 0.55 \\
\hline \hline
\end{tabular}

the relation between both data sets. The TLS and SWECCT tests are inversely related (Spearman correlation $=-0.59, p=0.001$ ).

To distinguish patients with CFS from nondisabled controls, both TLS and SWECCT test results were compiled. Figure 3 shows the results based on a logistic regression model with the TLS and SWECCT tests. Sensitivity (percentage of correctly classified patients with CFS), specificity (percentage of correctly classified nondisabled controls), and accuracy (total percentage of correctly classified subjects) have been calculated (Table 4). The same strategy was used based solely on TLS, solely on the SWECCT test, and based on combined TLS and SWECCT test results. When combined with SWECCT test results, the predictive value of TLS becomes even stronger.

\section{DISCUSSION}

This is the first study examining the relation between walking and vision in female patients with CFS. In response to the study's three aims, we first can conclude that gait automaticity is impaired in female patients with CFS compared with nondisabled controls. Of patients with CFS, 55.9 percent stopped walking compared with

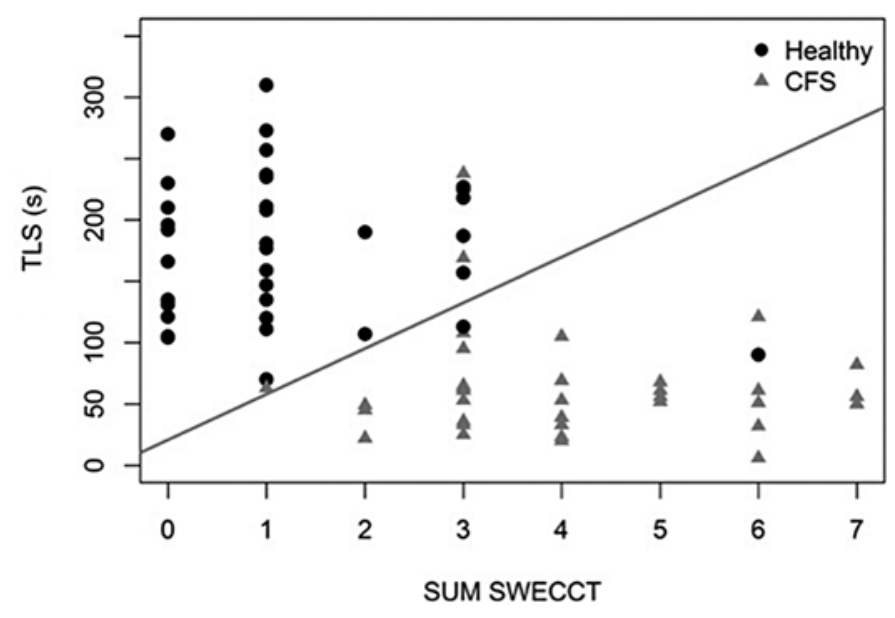

Figure 3.

Scatter diagram of "stops walking with eyes closed with secondary cognitive task" (SWECCT) test versus timed loaded standing (TLS) test. Line shows discrimination between nondisabled controls (healthy) and female patients with chronic fatigue syndrome (CFS) based on logistic regression with TLS and SWECCT test. 
Table 4.

Sensitivity, specificity, and accuracy percentages for both timed loaded standing (TLS) and dual tasking (DT) tests alone or together using logistic regression model as shown in Figure 3.

\begin{tabular}{lccc}
\hline \multicolumn{1}{c}{ Test } & Sensitivity & Specificity & Accuracy \\
\hline TLS Alone & 88 & 89 & 89 \\
DT Alone & 88 & 82 & 85 \\
TLS and DT & 91 & 95 & 93 \\
\hline \hline
\end{tabular}

only 5.3 percent of nondisabled controls when completing a cognitive task with eyes closed. Second, the testretest reliability of the SWECCT test used for assessing gait automaticity in patients with CFS is moderate. Third, results obtained with the SWECCT test were inversely related (Spearman correlation $=-0.59, p=0.001$ ) to the TLS test, showing an inverse relation between gait automaticity and trunk arm endurance in female patients with CFS. Combined with the SWECCT test results, the predictive value of TLS becomes even stronger.

Comparing our data with previous findings is impossible because no DT test has been used previously in studies examining patients with CFS. However, the present observations might explain in part why patients with CFS often report difficulties when walking for a prolonged time [3-5] and are unable to reach the recommended 10,000 steps per day [25]. These limitations may also result from their fatigue [25].

In addition, the results of Paul et al.'s work, which note that patients with CFS walked slower but also at a higher cost at matched-velocity than nondisabled controls, can be understood based on lost automaticity [25-26].

Current rehabilitation guidelines for patients with CFS prescribe graded exercise therapy (GET) and cognitive behavioral therapy. If the present findings are confirmed by others and if future work shows that the observed reduced gait automaticity in patients with CFS is of clinical importance, adding gait automaticity training to current rehabilitation programs for CFS seems warranted [45-47].

\section{STUDY LIMITATIONS}

A few methodological issues regarding the present study must be mentioned. Regarding the subjects, since only women were studied, external validity of the results is therefore limited to female adult patients with CFS. A few parameters of the included participants were not taken into account, such as menopausal state and levels of education, intelligence, and socioeconomic status.

Another limitation could be that patients with CFS had more or greater vision problems than the control group. Also, tests for assessing the participants' mathematical skills with both eyes open could have been performed to further examine the comparability of the two groups.

Blinding of the assessor was practically impossible because the nondisabled control population consisted of healthy nurses and doctors wearing their hospital uniforms. Hence, future studies should examine whether the observed differences remain when using blinded assessors. Given the use of hospital staff as control subjects, familiarity of the setting differed between groups. This might have affected the study findings in a way that overestimates the differences between the two groups.

Since there was only one observer for examining the reliability of the SWECCT test in patients with CFS, studies examining the test's interobserver reliability, validity, and responsiveness to change are needed. The test could be repeated using up to three observers or using a video camera to score results later using as many observers as needed.

The cross-sectional nature of the study has its limitations. Longitudinal data are required to examine the stability of these findings in a condition such as CFS, which is characterized by high health-status fluctuations over time.

Although this study was a pilot study with only a limited number of participants and without a formal a priori power calculation, significant differences between patients with CFS and nondisabled controls could be demonstrated. However, additional data are needed to confirm these results.

The SWECCT test has been shown to generate reliable data. Comparison with a gold standard could help to demonstrate its true validity. When combined with TLS results, SWECCT test results gain a stronger predictive value to discriminate between patients with CFS and nondisabled controls.

Hence, more research is needed to underpin these findings and their implications for treatment. Comparing both physical outcomes with data of three psychological tests (the RAND 36-Item Health Survey, Symptom Checklist 90, and Checklist Individual Strength) in the same CFS population could help us to understand these functional findings. Results of this study will be published later. 


\section{CONCLUSIONS}

Taking the study limitations into account, the present study suggests that gait automaticity is impaired in female patients with CFS compared with nondisabled controls. We found the test-retest reliability of the SWECCT test for assessing gait automaticity in patients with CFS to be moderate. The test-retest reliability is moderate for point C - that part of the test in which subjects had to add a cognitive function when walking with eyes closed-and for global stopping of the SWECCT test.

Further work, including possible adaptations to the test, is required to improve the reliability of all parts of the SWECCT test for patients with CFS. Future studies should examine the test's test-retest reliability, inter- and intrarater validity, and responsiveness to change in a condition characterized by fluctuations.

Finally, the study data indicate that impairments in gait automaticity in patients with CFS are inversely related to combined trunk and arm endurance. When both tests are combined, a stronger predictive value is obtained to discriminate between patients with CFS and nondisabled controls. More research is needed, e.g., addressing the loss of gait automaticity as a treatment plan and/or including a program prior to GET to address this specific problem.

\section{ACKNOWLEDGMENTS}

\author{
Author Contributions: \\ Study concept and design: J. b Eyskens. \\ Acquisition, analysis, and interpretation of data: J. b Eyskens. \\ Drafting of manuscript: J. b Eyskens, J. Nijs. \\ Critical revision of manuscript for important intellectual content: \\ G. Moorkens, K. Wouters, J. Nijs. \\ Statistical analysis: K. Wouters. \\ Study supervision: G. Moorkens.
}

Financial Disclosures: The authors have declared that no competing interests exist.

Funding/Support: This material was unfunded at the time of manuscript preparation.

Additional Contributions: Suggestions and advice have been given to all of us during the process of developing this article. We thank all for their help but especially wish to mention Hugo Stuer, MD; Bart Leroy, MD; and Luc De Nil, MSc, PT, for the many hours discussing CFS in an inter- and transdisciplinary way. We would also like to thank the staff of the Antwerp University Hospital (Antwerp, Belgium) for administrative, technical, and material support.

Institutional Review: The study protocol was approved by the Ethics Committee of the University Hospital Antwerp and written informed consent was obtained from all study participants.
Participant Follow-up: The authors plan to inform participants for whom contact information is available of the publication of this study.

\section{REFERENCES}

1. Fukuda K, Straus SE, Hickie I, Sharpe MC, Dobbins JG, Komaroff A; International Chronic Fatigue Syndrome Study Group. The chronic fatigue syndrome: A comprehensive approach to its definition and study. Ann Intern Med. 1994;121(12):953-59. [PMID:7978722] http://dx.doi.org/10.7326/0003-4819-121-12-199412150$\underline{00009}$

2. Hutchinson CV, Badham SP. Patterns of abnormal visual attention in myalgic encephalomyelitis. Optom Vis Sci. 2013;90(6):607-14. [PMID:23689679] http://dx.doi.org/10.1097/OPX.0b013e318294c232

3. Nijs J, Vaes P, McGregor N, Van Hoof E, De Meirleir K. Psychometric properties of the Dutch Chronic Fatigue Syndrome-Activities and Participation Questionnaire (CFSAPQ). Phys Ther. 2003;83(5):444-54. [PMID:12718710]

4. Nijs J, Vaes P, De Meirleir K. The Chronic Fatigue Syndrome Activities and Participation Questionnaire (CFSAPQ): An overview. Occup Ther Int. 2005;12(2):107-21. [PMID:16136868] http://dx.doi.org/10.1002/oti.19

5. Freeman R, Komaroff AL. Does the chronic fatigue syndrome involve the autonomic nervous system? Am J Med. 1997;102(4):357-64. [PMID:9217617] http://dx.doi.org/10.1016/S0002-9343(97)00087-9

6. Shipp KM, Purse JL, Gold DT, Pieper CF, Sloane R, Schenkman M, Lyles KW. Timed loaded standing: A measure of combined trunk and arm endurance suitable for people with vertebral osteoporosis. Osteoporos Int. 2000; 11(11):914-22. [PMID:11193243] http://dx.doi.org/10.1007/s001980070029

7. Eyskens JB, Nijs J, D’Aût K, Sand A, Wouters K, Moorkens G. Timed loaded standing in female chronic fatigue syndrome compared with other populations. J Rehabil Res Dev. 2015;52(1):21-30. [PMID:26230614] http://dx.doi.org/10.1682/JRRD.2014.03.0086

8. Corlett EN. Pain, posture, and performance. In: Corlett EN, Richardson J, editors. Stress, work design, and productivity. Chichester (NY): Wiley; 1981. p. 27-42.

9. Hägg G. Static work and myalgia-A new explanation model. In: Andersson PA, Hobart DJ, Danoff JV, editors. Electromyography and kinesiology. Amsterdam (the Netherlands): Elsevier Science; 1991. p. 141-44.

10. Hägg GM. Human muscle fibre abnormalities related to occupational load. Eur J Appl Physiol. 2000;83(2-3):159-65. [PMID:11104056] http://dx.doi.org/10.1007/s004210000274 
11. Hägg GM, Aström A. Load pattern and pressure pain threshold in the upper trapezius muscle and psychosocial factors in medical secretaries with and without shoulder/ neck disorders. Int Arch Occup Environ Health. 1997; 69(6):423-32. [PMID:9215929] http://dx.doi.org/10.1007/s004200050170

12. Zetterberg C, Forsman M, Richter HO. Effects of visually demanding near work on trapezius muscle activity. J Electromyogr Kinesiol. 2013;23(5):1190-98. [PMID:23911117] http://dx.doi.org/10.1016/j.jelekin.2013.06.003

13. Li G, Haslegrave CM. Seated work postures for manual, visual and combined tasks. Ergonomics. 1999;42(8):1060-86. [PMID:10504890] http://dx.doi.org/10.1080/001401399185144

14. Kilbom A, Persson J, Jonsson BG. Disorders of the cervicobrachial region among female workers in the electronics industry. Int J Ind Ergon. 1986;1:37-47. http://dx.doi.org/10.1016/0169-8141(86)90006-5

15. Haslegrave CM. What do we mean by a 'working posture'? Ergonomics. 1994;37(4):781-99. [PMID:8187755] http://dx.doi.org/10.1080/00140139408963688

16. Sporrong H, Palmerud G, Kadefors R, Herberts P. The effect of light manual precision work on shoulder muscles-an EMG analysis. J Electromyogr Kinesiol. 1998; 8(3):177-84. [PMID:9678152] http://dx.doi.org/10.1016/S1050-6411(97)00032-1

17. Laville A. Postural stress in high-speed precision work. Ergonomics. 1985;28(1):229-36. [PMID:3996359] http://dx.doi.org/10.1080/00140138508963130

18. Matthis JS, Fajen BR. Visual control of foot placement when walking over complex terrain. J Exp Psychol Hum Percept Perform. 2014;40(1):106-15. [PMID:23750964] http://dx.doi.org/10.1037/a0033101

19. Woollacott M, Shumway-Cook A. Attention and the control of posture and gait: A review of an emerging area of research. Gait Posture. 2002;16(1):1-14. [PMID:12127181] http://dx.doi.org/10.1016/S0966-6362(01)00156-4

20. Montero-Odasso M, Verghese J, Beauchet O, Hausdorff JM. Gait and cognition: A complementary approach to understanding brain function and the risk of falling. J Am Geriatr Soc. 2012;60(11):2127-36. [PMID:23110433] http://dx.doi.org/10.1111/j.1532-5415.2012.04209.x

21. Regnaux JP, Daniel D. [Attention during walking: Evaluation of automaticity with a dual task paradigm.] Proceedings of the XXIX Congres de la Société de Biomécanique; 2004 Sep 8-10; Creteil, France. French.

22. Verghese J, Buschke H, Viola L, Katz M, Hall C, Kuslansky G, Lipton R. Validity of divided attention tasks in predicting falls in older individuals: A preliminary study. J Am Geriatr Soc. 2002;50(9):1572-76. [PMID:12383157] http://dx.doi.org/10.1046/j.1532-5415.2002.50415.x
23. MacAulay RK, Brouillette RM, Foil HC, Bruce-Keller AJ, Keller JN. A longitudinal study on dual-tasking effects on gait: cognitive change predicts gait variance in the elderly. PLoS One. 2014;9(6):e99436. [PMID:24905590] http://dx.doi.org/10.1371/journal.pone.0099436

24. Bock O. Dual-task costs while walking increase in old age for some, but not for other tasks: An experimental study of healthy young and elderly persons. J Neuroeng Rehabil. 2008;5:27. [PMID:19014544] http://dx.doi.org/10.1186/1743-0003-5-27

25. Paul L, Rafferty D, Wood L, Maclaren W. Gait characteristics of subjects with chronic fatigue syndrome and controls at self-selected and matched velocities. J Neuroeng Rehabil. 2008;5:16. [PMID:18505580] http://dx.doi.org/10.1186/1743-0003-5-16

26. Paul L, Rafferty D, Marshal R. Physiological cost of walking in those with chronic fatigue syndrome (CFS): A casecontrol study. Disabil Rehabil. 2009;31(19):1598-1604. [PMID:19848558] http://dx.doi.org/10.1080/09638280802652015

27. Potaznick W, Kozol N. Ocular manifestations of chronic fatigue and immune dysfunction syndrome. Optom Vis Sci. 1992;69(10):811-14. [PMID:1437004] http://dx.doi.org/10.1097/00006324-199210000-00011

28. Caffery BE, Josephson JE, Samek MJ. The ocular signs and symptoms of chronic fatigue syndrome. J Am Optom Assoc. 1994;65(3):187-91. [PMID:8201170]

29. Badham SP, Hutchinson CV. Characterising eye movement dysfunction in myalgic encephalomyelitis/chronic fatigue syndrome. Graefes Arch Clin Exp Ophthalmol. 2013; 251(12):2769-76. [PMID:23918092] http://dx.doi.org/10.1007/s00417-013-2431-3

30. Hutchinson CV, Maltby J, Badham SP, Jason LA. Visionrelated symptoms as a clinical feature of chronic fatigue syndrome/myalgic encephalomyelitis? Evidence from the DePaul Symptom Questionnaire. Br J Ophthalmol. 2014; 98(1):144-45. [PMID:24187048] http://dx.doi.org/10.1136/bjophthalmol-2013-304439

31. Ickmans K, Meeus M, De Kooning M, Lambrecht L, Pattyn $\mathrm{N}$, Nijs J. Can recovery of peripheral muscle function predict cognitive task performance in chronic fatigue syndrome with and without fibromyalgia? Phys Ther. 2014; 94(4): 511-22. [PMID:24363336]

http://dx.doi.org/10.2522/ptj.20130367

32. Ickmans K, Meeus M, Kos D, Clarys P, Meersdom G, Lambrecht L, Pattyn N, Nijs J. Cognitive performance is of clinical importance, but is unrelated to pain severity in women with chronic fatigue syndrome. Clin Rheumatol. 2013;32(10):1475-85. [PMID:23737111] http://dx.doi.org/10.1007/s10067-013-2308-1

33. Just MA, Carpenter PA. A capacity theory of comprehension: Individual differences in working memory. Psychol 
Rev. 1992;99(1):122-49. [PMID:1546114]

http://dx.doi.org/10.1037/0033-295X.99.1.122

34. Mulder T, Appelman M. De geboren aanpasser: Over beweging, bewustzijn en gedrag. Amsterdam (the Netherlands): Contact; 2001. Dutch.

35. Mulder T, Zijlstra W, Geurts A. Assessment of motor recovery and decline. Gait Posture. 2002;16(2):198-210. [PMID:12297260] http://dx.doi.org/10.1016/S0966-6362(01)00157-6

36. Land MF, Hayhoe M. In what ways do eye movements contribute to everyday activities? Vision Res. 2001;41(25-26): 3559-65. [PMID:11718795] http://dx.doi.org/10.1016/S0042-6989(01)00102-X

37. Lundin-Olsson L, Nyberg L, Gustafson Y. "Stops walking when talking" as a predictor of falls in elderly people. Lancet. 1997;349(9052):617. [PMID:9057736] http://dx.doi.org/10.1016/S0140-6736(97)24009-2

38. Hyndman D, Ashburn A. Stops walking when talking as a predictor of falls in people with stroke living in the community. J Neurol Neurosurg Psychiatry. 2004;75(7):994-97. [PMID:15201358] http://dx.doi.org/10.1136/jnnp.2003.016014

39. Canning CG, Ada L, Paul SS. Is automaticity of walking regained after stroke? Disabil Rehabil. 2006;28(2):97-102. [PMID:16393839] http://dx.doi.org/10.1080/09638280500167712

40. Bowen A, Wenman R, Mickelborough J, Foster J, Hill E, Tallis R. Dual-task effects of talking while walking on velocity and balance following a stroke. Age Ageing. 2001; 30(4):319-23. [PMID:11509310] http://dx.doi.org/10.1093/ageing/30.4.319

41. Tseng BY, Cullum CM, Zhang R. Older adults with amnestic mild cognitive impairment exhibit exacerbated gait slowing under dual-task challenges. Curr Alzheimer Res. 2014;11(5):494-500. [PMID:24801217] http://dx.doi.org/10.2174/1567205011666140505110828

42. Chronic fatigue syndrome [Internet]. Atlanta (GA): U.S. Centers for Disease Control and Prevention; 2015 [updated 2015 Apr 7]. Available from: http://www.cdc.gov/cfs/

43. Axelsson J. Quality and ergonomics: Towards a successful integration [thesis]. Linköping (Sweden): Department of Management and Engineering, Linköping University; 2000.
44. Landis JR, Koch GG. The measurement of observer agreement for categorical data. Biometrics. 1977;33(1):159-74. [PMID:843571] http://dx.doi.org/10.2307/2529310

45. Fulcher KY, White PD. Randomised controlled trial of graded exercise in patients with the chronic fatigue syndrome. BMJ. 1997;314(7095):1647-52. [PMID:9180065] http://dx.doi.org/10.1136/bmj.314.7095.1647

46. Dougall D, Johnson A, Goldsmith K, Sharpe M, Angus B, Chalder T, White P. Adverse events and deterioration reported by participants in the PACE trial of therapies for chronic fatigue syndrome. J Psychosom Res. 2014;77(1): 20-26. [PMID:24913337] http://dx.doi.org/10.1016/j.jpsychores.2014.04.002

47. Sharpe M, Hawton K, Simkin S, Surawy C, Hackmann A, Klimes I, Peto T, Warrell D, Seagroatt V. Cognitive behaviour therapy for the chronic fatigue syndrome: A randomized controlled trial. BMJ. 1996;312(7022):22-26.

[PMID:8555852]

http://dx.doi.org/10.1136/bmj.312.7022.22

Submitted for publication November 26, 2014. Accepted in revised form June 17, 2015.

This article and any supplementary material should be cited as follows:

Eyskens JB, Nijs J, Wouters K, Moorkens G. Reduced gait automaticity in female patients with chronic fatigue syndrome: Case-control study. J Rehabil Res Dev. 2015; 52(7):805-14.

http://dx.doi.org/10.1682/JRRD.2014.11.0293

ResearcherID: Jan b Eyskens, MSc PT, DO, Pr Ph: B8552-2015; Jo Nijs, PhD: B-3336-2011; Greta Moorkens, MD, PhD: B-8776-2015

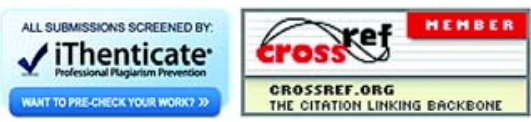

